\title{
Optical Study on Deposed Polystyrene Doped DCM Laser Dye Thin Films at Different Temperature
}

\author{
Akeel Shaker Tuhaiwer \\ Muthanna University, College of Science, Physics Department, Al- Muthanna, Samawa, Iraq \\ E-mail address: AkeelShaker2000@gmail.com
}

Keywords: PS, DCM, optical properties, thin films, cast method

\begin{abstract}
Polystyrene (PS) polymer doped with DCM laser dye thin films have prepared on glass substrate using casting method. The obtained PS doped with DCM thin films were treated at different annealing temperatures such $(30,40,50,60,70){ }^{\circ} \mathrm{C}$. It was observed from result that the allowed direct electronic transitions energy gap was increased from 2.21 up to $2.3 \mathrm{e} . \mathrm{V}$ as the temperature increasing from $30-70^{\circ} \mathrm{C}$. And the allowed indirect electronic transition energy gap rose from 0.06 to $0.15 \mathrm{e} . \mathrm{V}$ as the temperature increasing. The allowed indirect phonon energy also was decreased at the same range of temperature. The different effect of temperature variation was observed on the optical properties of PS doped with DCM thin films.
\end{abstract}

\section{Introduction}

Polymeric and other organic thin films and multilayers are important for a wide range of applications, including electronics, optoelectronics and sensors [1]. Solid polymeric materials undergo physical changes when heat is applied; this will usually result in undesirable changes to the properties of the material. A clear distinction needs to be made between thermal decomposition and thermal degradation [2].

Polymer blending has emerged as a cheaper and easier route to develop the polymeric materials. However, because of the large unfavorable enthalpy of mixing, most polymer blends tend to macro - phase separation which results in deterioration in properties $[3,4]$.

Changing in polymer composition may induce optical absorption. One method to enhance the optical and electrical properties of polymer is by adding laser dye as dopant in the system. Energy band structure is basic understandings on mechanism of optical properties which can be obtained by studying optical absorption. Although some work has been done on the optical properties of doped polymer thin films [5].

Polymers and organic materials have been increasingly used in electrical and optical devices $[6,7]$. Capability of electrical charge transfer and doping with different dyes makes them excellent candidates for organic light emitting diodes $[8,9]$. Due to weak molecular interactions in organic materials and random orientation of polymer chains to each other, the performance of these devices has significant dependence on the fabrication process.

Thermal treatment of polymer doped laser dye after casting step of their fabrication process may improve their optical properties [10].

The optical properties of DCM doped with PS polymer by A. N. Mohamed [11], he find out that the direct energy gap was $3.9 \mathrm{eV}$ for PS thin film, energy gap for PS-DCM thin film was $2.2 \mathrm{eV}$. While for indirect transitions the energy gap for PS thin film was $2.25 \mathrm{eV}$ and phonon energy was $0.55 \mathrm{eV}$, but the energy gap for PS-DCM film was $1.4 \mathrm{eV}$ and phonon energy was $0.5 \mathrm{eV}$.

This paper presents experimental results of effects of thermal annealing on the some optical properties of PS polymer of the chemical formula $\left(\mathrm{C}_{8} \mathrm{H}_{8}\right)_{n}$ and doped PS with DCM laser dye, [2-[2[4-(dimethylamino)phenyl]ethenyl]-6-methyl-4H- pyran-4-ylidene]-propanedinitrile and the chemical formula is $\mathrm{C}_{19} \mathrm{H}_{17} \mathrm{~N}_{3} \mathrm{O}$, thin films prepared using casting method.

Polystyrene belongs to the group of standard thermoplastics that also includes polyethylene, polypropylene, and poly (vinyl chloride). Because of its special properties polystyrene can be used in an extremely wide range of applications. Polystyrene an amorphous, optically clear thermoplastic 
material, which is flexible as thin films, is chosen as the host matrix because of its ideal properties for investigating the optical properties of the DCM laser dye. Polystyrene (PS) is in solid (glassy) state at room temperature but flows if heated above its glass transition temperature and becomes solid again when cooled. Introduction of DCM laser dye into polymeric matrices can in general, modify the optical, electrical and mechanical properties of the polymer.

Many researchers succeeded to prepare PS as films deposited on various substrates such as glass or silicon wafer $[12,13]$; this interest was by the technological importance of film.

Polystyrene (PS) films deposited on solid substrates are used in various areas of science and technology, including optical mechanical industry [14]. The determination of optical properties of the polymer is important for various optical applications.

\section{Experimental part}

To prepare PS doped with DCM thin films, firstly dissolving $0.015 \mathrm{gm}$ from DCM in $10 \mathrm{ml}$ THF solvent and stirrer about 30 minutes to obtain homogenous solution, then $2 \mathrm{gm}$ PS dissolve in $30 \mathrm{ml}$ THF with 2 hours vigorous stirring to get the polymer solution. To synthesis the final thin films, 2ml DCM solution mixed with $5 \mathrm{ml}$ PS solution and casting on glass substrate at room temperature. To study the temperature effect on the optical properties of the films, different temperatures applied on the final samples as $30,40,50,60,70{ }^{\circ} \mathrm{C}$. These samples marked as A, B, $\mathrm{C}, \mathrm{D}$, and $\mathrm{E}$ respectively.

Thin films thickness was measured using the optical interferometer method employing HeNe laser $0.632 \mu \mathrm{m}$, and found to $0.47 \mu \mathrm{m}$ for all samples.

The optical absorption and transmission spectra of DCM doped with PS thin films were recorded using UV-VIS double beam spectrometer in the wave length range from 190 to $1100 \mathrm{~nm}$. The absorption coefficient $(\alpha)$ was calculated using the equation [15]

$$
\alpha=\frac{2.303}{\mathrm{~d}} \mathrm{~A}
$$

The reflective index (n) of the thin films calculated from the equation [16]

$$
\mathrm{n}=\frac{1+\sqrt{\mathrm{R}}}{1-\sqrt{\mathrm{R}}}
$$

The extinction coefficient can be calculated in terms of the absorption coefficient using the equation [17]

$$
\mathrm{K}=\frac{\alpha \lambda}{4 \pi}
$$

The real and imaginary complex dielectric constant can be expressed by equations $(4,5)$ respectively[18][19]

$$
\begin{aligned}
& \varepsilon_{\mathrm{r}}=\mathrm{n}^{2}-\mathrm{K}^{2} \\
& \varepsilon_{\mathrm{i}}=2 \mathrm{nK}
\end{aligned}
$$

The optical conductivity of thin films can be calculated using the equation [20]

$$
\sigma=\frac{\alpha \mathrm{nc}}{4 \pi}
$$

\section{Results and Discussion}

The optical properties measurements for PS doped with DCM thin films at different temperatures were obtained using UV-VIS spectrophotometer on glass substrate. The absorbance of these films depends on the annealing temperature as shown in fig. (1). Furthermore there is a strong absorption band around 502nm similar to that of DCM in solution. 


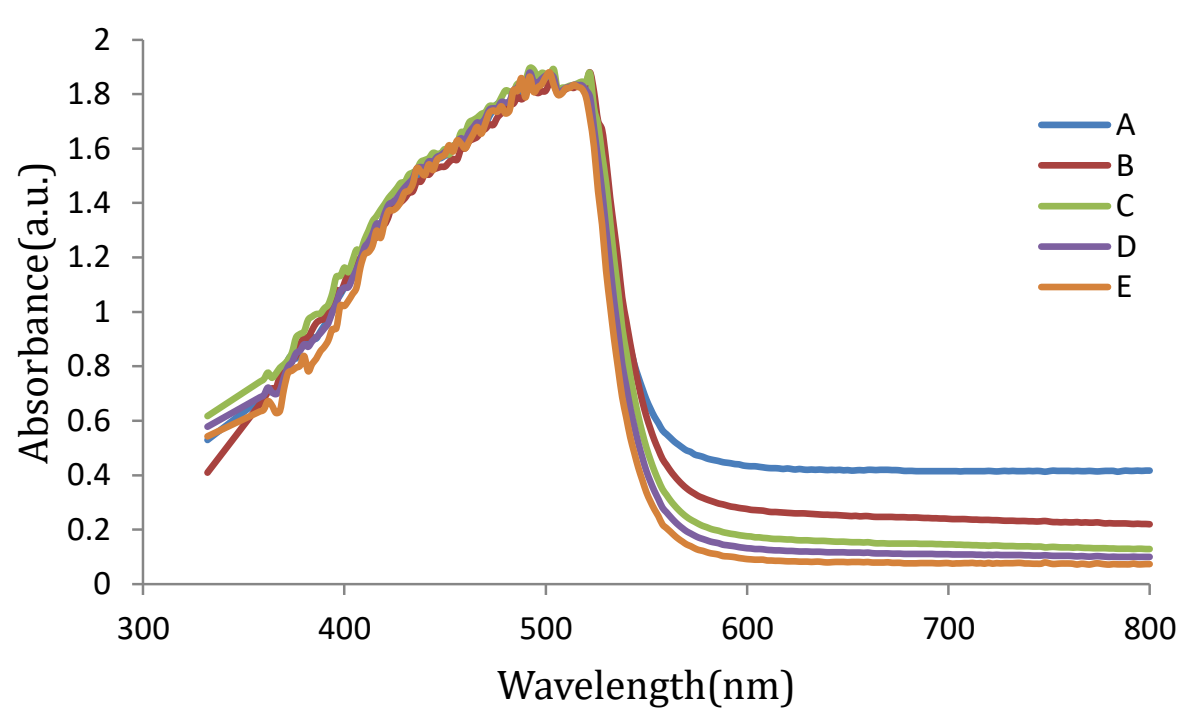

Fig. 1. Absorbance for PS doped with DCM thin films at different temperatures

The optical reflectance measurements for PS doped with DCM thin films at different temperatures depend on the annealing temperature as shown in fig.(2) for all films, it was observed that the optical reflectance increases with increases the annealing temperature.

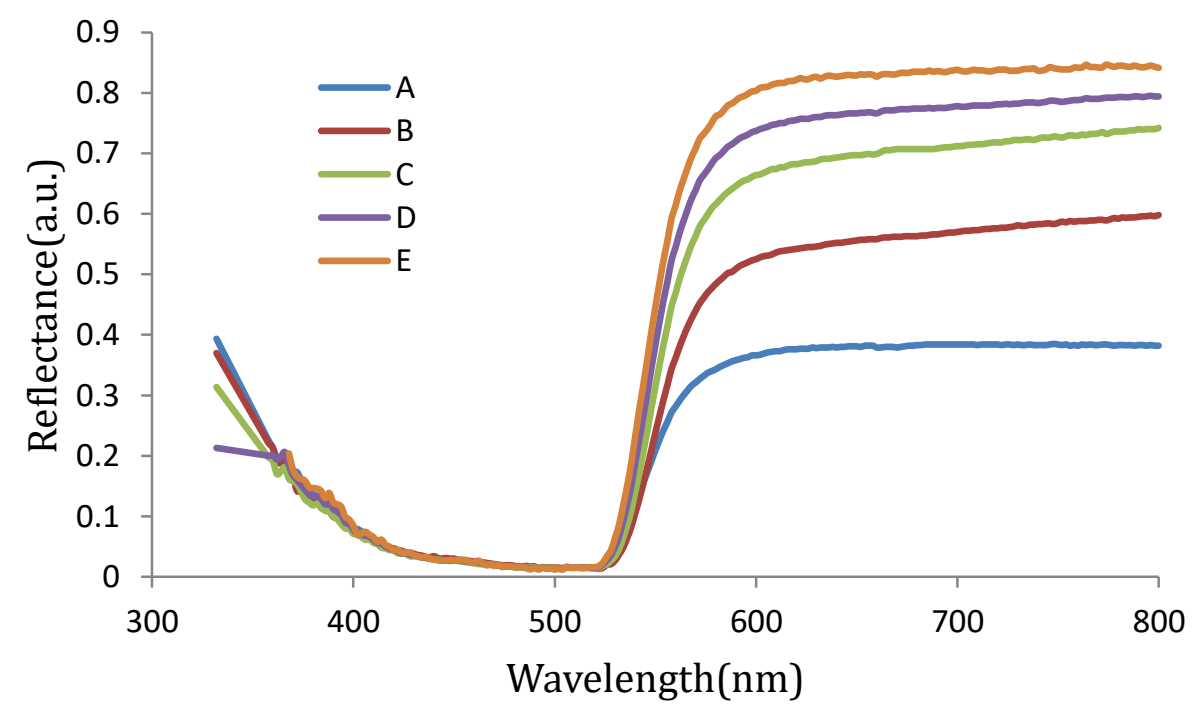

Fig. 2. Reflectance for PS doped with DCM thin films at different temperatures

Figure (3) shows the absorption coefficient for PS doped with DCM thin films at different temperatures determined from absorbance measurements using equation (1). The absorption coefficient of these films increases sharply in the UV range, and then decreased gradually in the visible region because it is inversely proportional to the transmittance. Generally, the absorption coefficient is increasing with the annealing temperature increasing. 


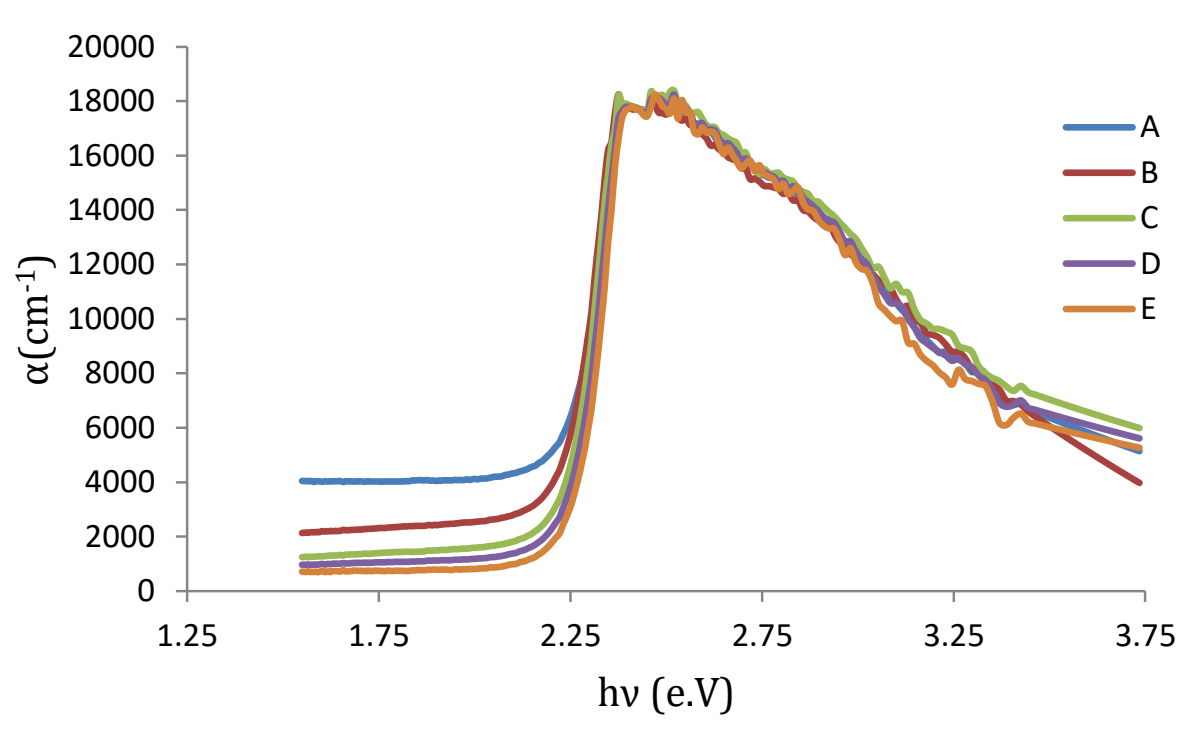

Fig. 3. Absorption coefficient for PS doped with DCM thin films at different temperatures The energy gap can be calculated from equation [21]

$$
\alpha h v=C\left(h v-E_{g}\right)^{n}
$$

where $\mathrm{C}$ is Constant controlled by specimen structure.

The relations drawn between $(\alpha h v)^{2},(\alpha h v)^{1 / 2}$ and photon energy (hv), as shown in fig. (4) and (5) which illustrates allowed direct electronic transition and fig. (4) illustrates allowed indirect electronic transition. The energy gap value depends on the films deposition conditions and its preparation method [22]. Also, the allowed indirect phonon energy $\left(E_{p}\right)$ was calculated from fig. (5).

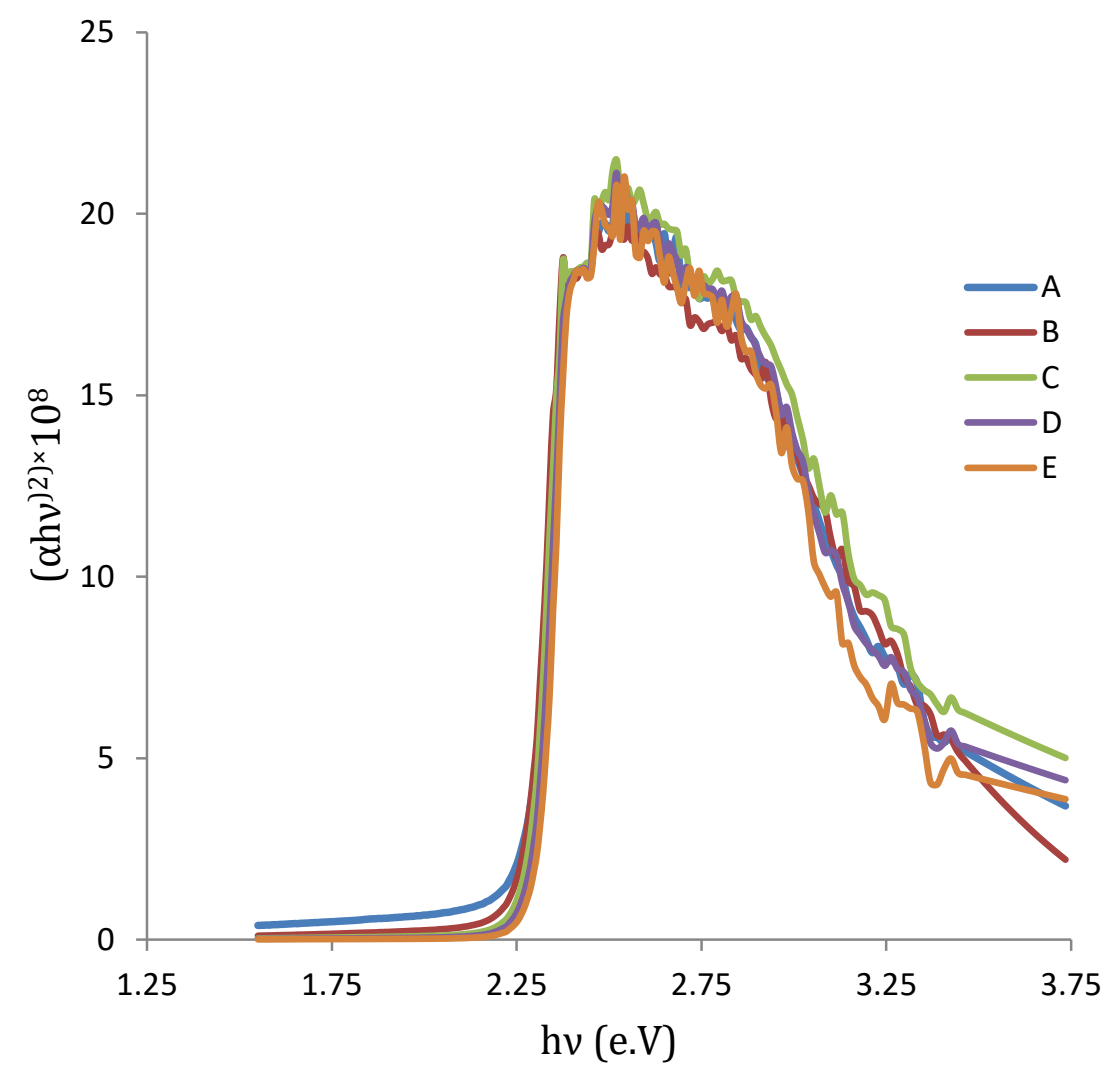

Fig. 4. Relationship between $(\alpha h v)^{2}$ and photon energy (e.V) 


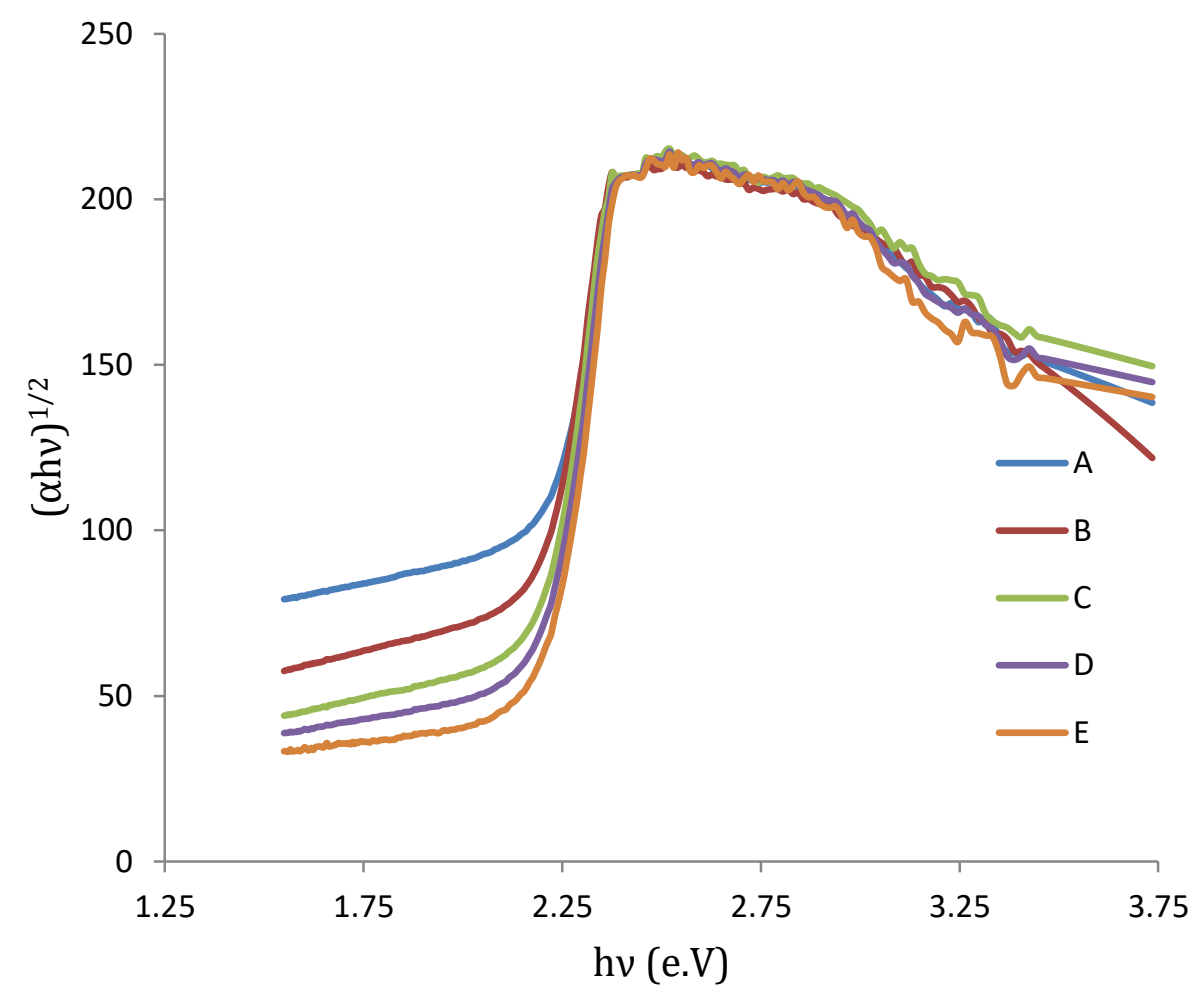

Fig. 5. Relationship between $(\alpha h v)^{1 / 2}$ and photon energy (e.V)

The energy gap values for direct and indirect for all thin films are summarized in table (1).

Table 1. Electronic transitions energy gap (e.V) and phonon energy (e.V) for PS doped with DCM thin films.

\begin{tabular}{|c|c|c|c|c|}
\hline Sample & $\begin{array}{c}\text { Temperature } \\
\left({ }^{\circ} \mathrm{C}\right)\end{array}$ & $\begin{array}{c}\text { Allowed } \\
\text { direct band } \\
\text { gap (e.V) }\end{array}$ & $\begin{array}{c}\text { Allowed } \\
\text { indirect band } \\
\text { gap (e.V) }\end{array}$ & $\begin{array}{c}\text { Allowed indirect } \\
\text { phonon energy } \\
(\mathrm{e} . \mathrm{V})\end{array}$ \\
\hline $\mathrm{A}$ & 30 & 2.21 & 0.06 & 2.03 \\
\hline $\mathrm{B}$ & 40 & 2.225 & 0.075 & 1.985 \\
\hline $\mathrm{C}$ & 50 & 2.25 & 0.09 & 1.94 \\
\hline $\mathrm{D}$ & 60 & 2.27 & 0.105 & 1.865 \\
\hline $\mathrm{E}$ & 70 & 2.3 & 0.15 & 1.79 \\
\hline
\end{tabular}

From table (1), one can be observed that the energy gap for allowed direct and indirect electronic transitions $(\mathrm{Eg})$ is increasing with the increasing of annealing temperature for all films. Where this energy was $2.21 \mathrm{e} . \mathrm{V}$ for sample annealed at $30^{\circ} \mathrm{C}$ (sample A) and increasing gradually reaching to $2.3 \mathrm{e} . \mathrm{V}$ for the sample $\mathrm{E}$ which annealed at $70^{\circ} \mathrm{C}$. Also this effect observed for indirect energy gap which increasing from $0.6 \mathrm{e} . \mathrm{V}$ for sample A to $0.15 \mathrm{e} . \mathrm{V}$ for sample E. While the phonon energy in case of allowed indirect transitions values were observed to be decreased with increasing the annealing temperature for all films. The calculations shown that the photon energy was $2.03 \mathrm{e} . \mathrm{V}$ for sample annealed at $30^{\circ} \mathrm{C}$, and this energy was dropped to $1.79 \mathrm{e} . \mathrm{V}$ for the film annealed at $70^{\circ} \mathrm{C}$.

The refractive indices for PS doped with DCM thin films at different temperatures were determined from equation (2). Figure (6) shows the variation in refractive index of these films in the wavelength range of $(300-800 \mathrm{~nm})$. The increasing in the annealing temperature results an increase in the refractive index in the visible/ near infrared region, but the refractive index tends to be unaffected at the UV region. 


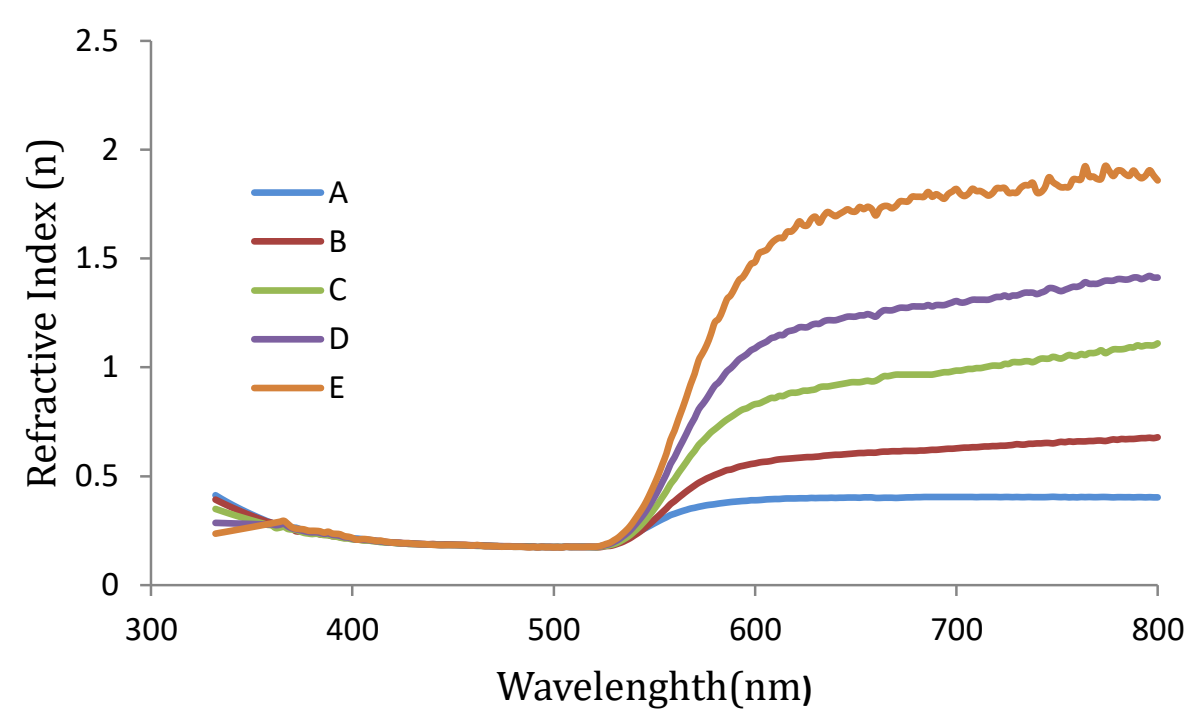

Fig. 6. Refractive index against the wavelength(nm)

Many semiempirical group contribution methods derived from the refractive indices of organic polymers have been established. These group contribution calculations are based on the molecular weight, the density of polymer, and the chemical structure of the polymer. The refraction values corresponding to group contribution models such as Lorentz-Lorenz, Glastone-Dale, Volgel, and Looyenga have been collected by VanKervelen [23]

Extinction coefficient (K) was calculated using th equation (3). The change of the extinction coefficient for PS doped with DCM thin films at different temperatures is shown in fig. (7).

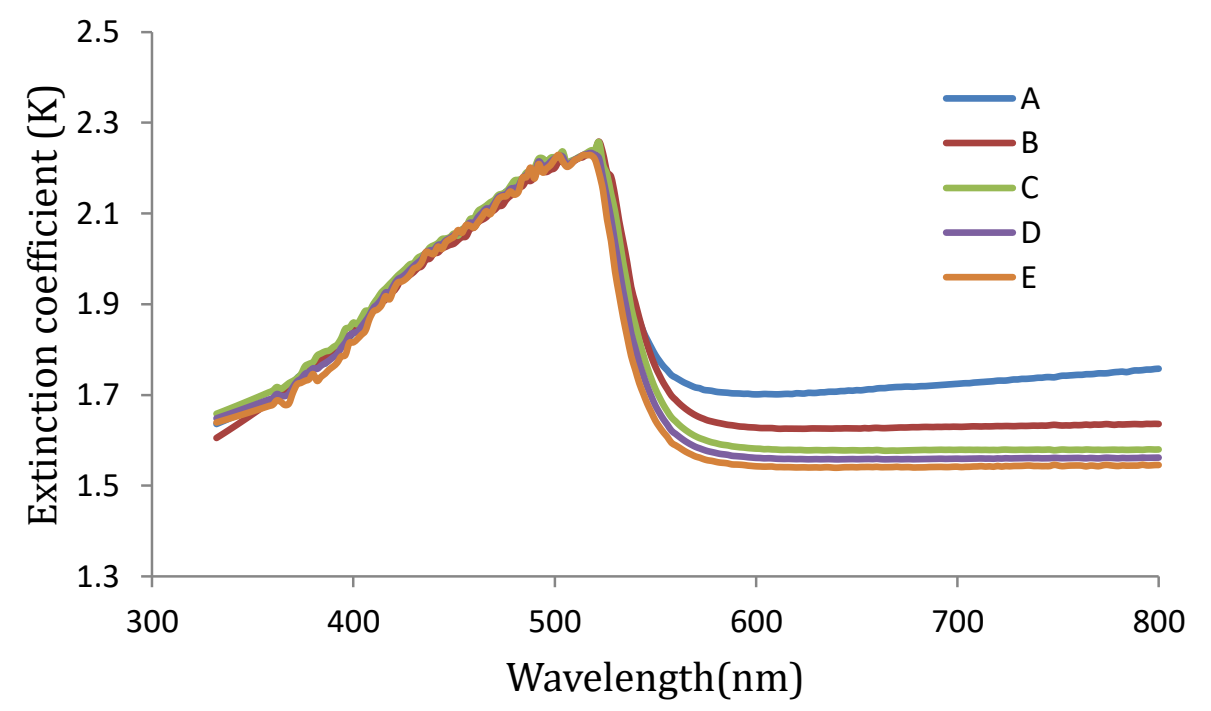

Fig. 7. Extinction coefficient against the wavelength(nm)

It can be noted that the extinction coefficient is of lowering values at low temperatures. Extinction coefficient behaves in the same behavior of absorption spectrum since they are joined mathematically. 
Both real and imaginary parts of dielectric constants were calculated for prepared thin films using equations (4) and (5) respectively. Figures (8) and (9) illustrate variation of real and imaginary parts of dielectric constants as a function of wavelengths.

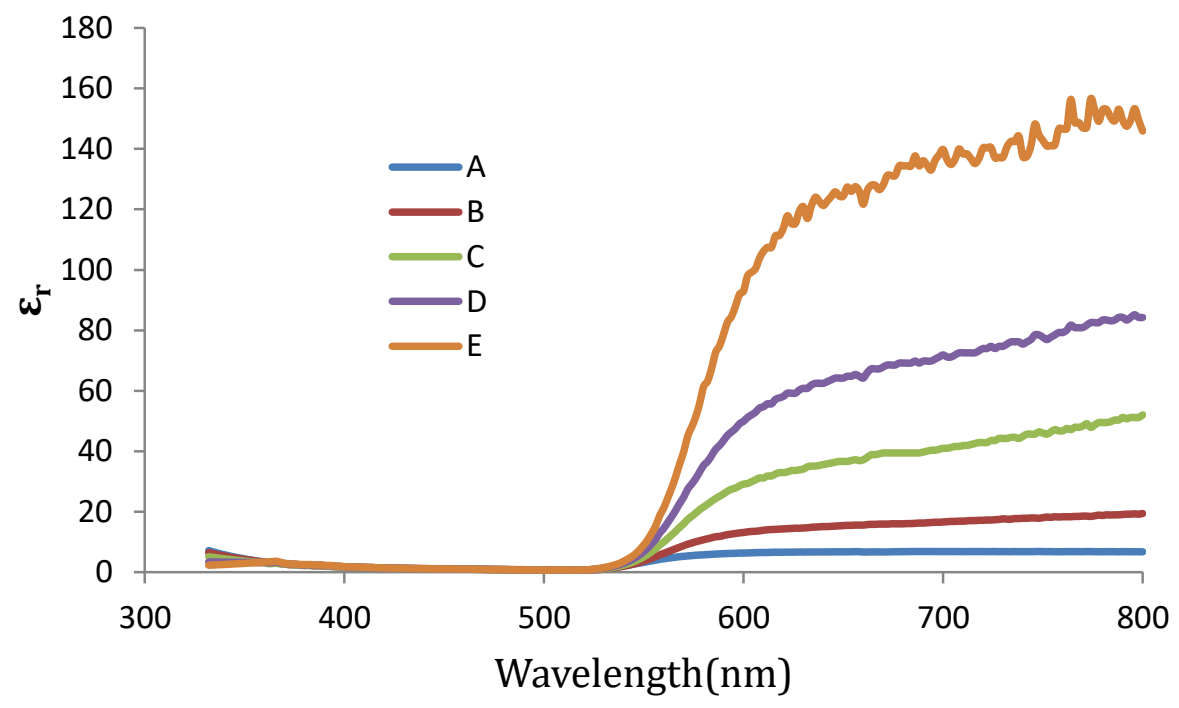

Fig. 8. Real part dielectric constant against the wavelength(nm)

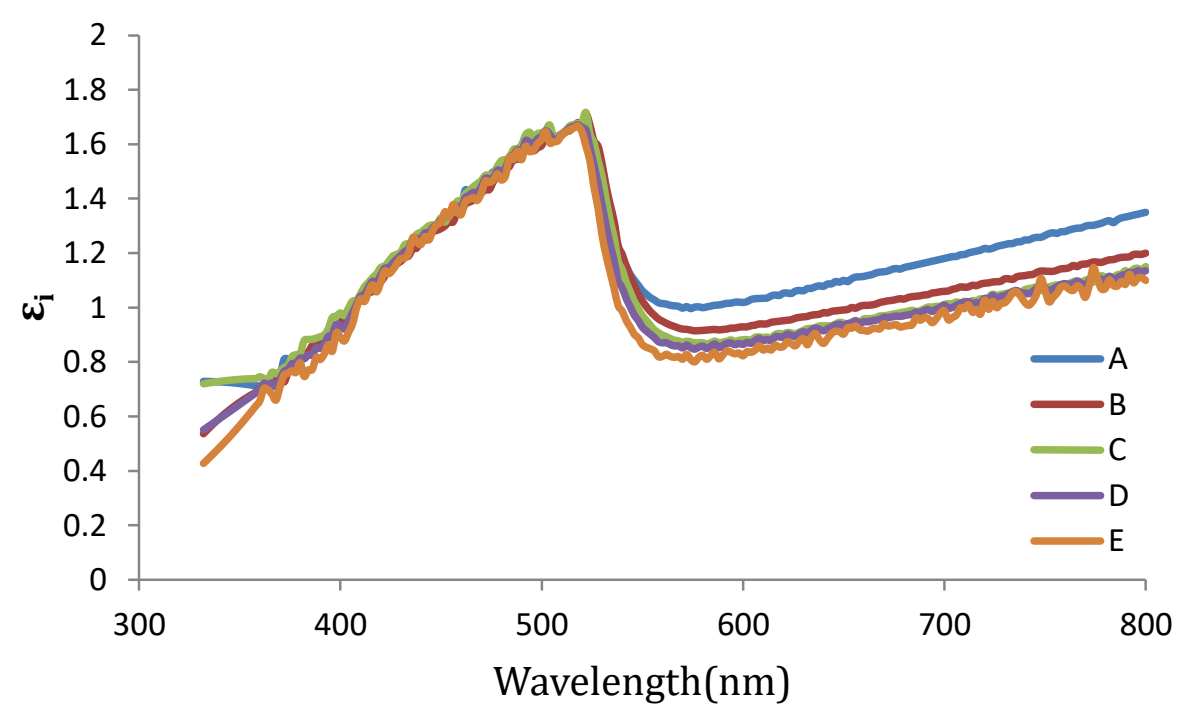

Fig. 9. Imaginary part dielectric constant against the wavelength(nm)

From figures (8) and (9), one can see that in all films the real part behaves as the refractive index because of the smaller values of $\left(\mathrm{K}^{2}\right)$ compared to $\left(\mathrm{n}^{2}\right)$, while the imaginary part depends mainly on $(\mathrm{K})$ values, which is related to the variation of absorption coefficient.

Figure (10) shows the variation of optical conductivity as a function of photon energy at different annealing temperatures. The optical conductivity was calculated using equation (6). 


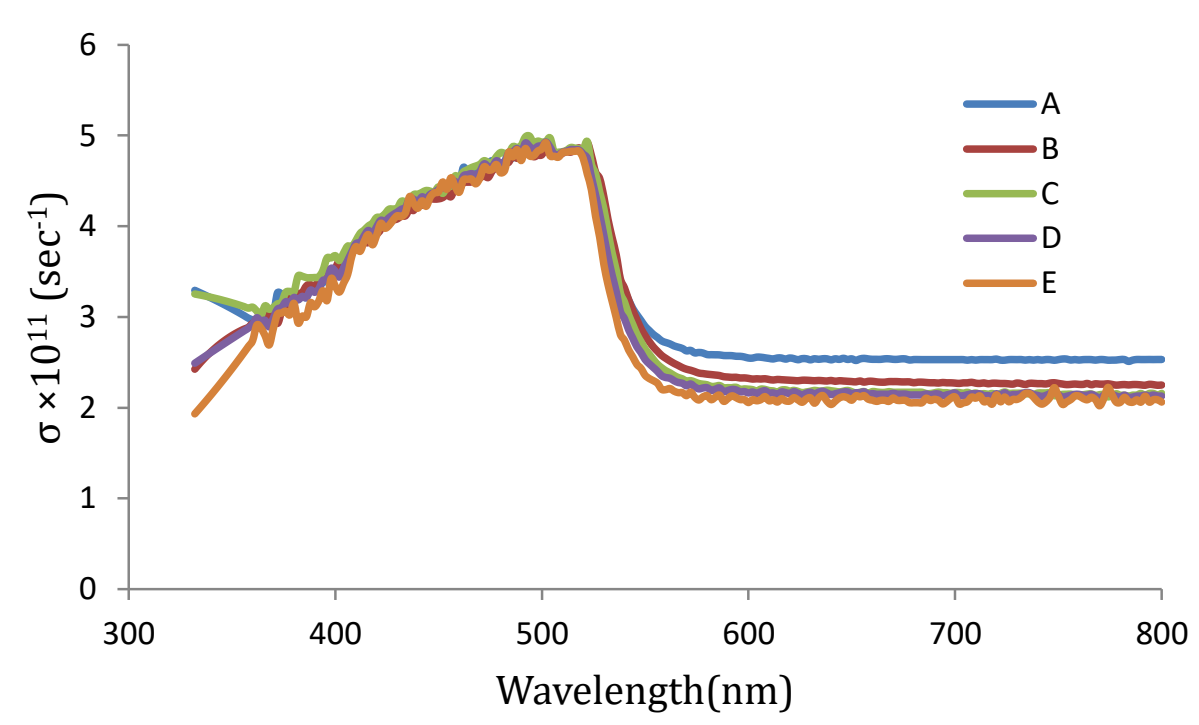

Fig. 10. Optical conductivity as a function of photon energy

The optical conductivity is increases with increasing the photon energy, this increasing due to electron excited by photon energy. The optical conductivity of the thin films was decreasing with increasing the annealing temperature.

\section{Conclusion}

Pure polystyrene and DCM doped with polystyrene thin films were prepared casting method was used in this work and the effect of the annealing temperature on the optical properties was studied using UV-VIS spectrometer. Increasing of the annealing temperature for all films causing a decreasing in the direct and indirect electronic transitions, this increasing also results an increase in the refractive index, while it causing decreasing in extinction coefficient and the optical conductivity for all films.

\section{References}

[1] A. Pique, R.C.Y. Auyeung, J.L. Stepnowski, D.W. Weir, C.B. Arnold, R.A. McGill, D.B. Chrisey," Laser processing of polymer thin films for chemical sensor applications" Surface and Coatings Technology 163-164(2003),293-299.

[2] T. Kashiwagi and A. Inabi, "Behavior of Primary Radicals during Thermal Degradation of Poly(methyl methacrylate)", Polymer Degradation and Stability, 26(1989),161- 184.

[3] D.R Paul, and C. B. Bucknall, "Polymer Blends", Willey Interscience, New York (2000).

[4] C. Harrats, S. Thomas, and G. Groeninckx, "Micro - and Nanostructured Multiphase Polymer Blend Systems", Taylor \& Francis Group, Boca Raton (2006).

[5] Ahmed Namah Mohamed, Akeel Shaker Tuhaiwer, Zaid Saud Razzaq, " Optical Properties of Polyvinyl Chloride Doped with DCM dye Thin Films" 30(2016),45-56.

[6] Galatsis, K.; Wang, K.; Botros, Y.; Yang, Y.; Xie, Y.H.; Stoddart, J.; Kaner, R.B.; Ozhan, C.;Liu, J.; Ozkan, M. "Emerging memory devices", IEEE Circuits and Devices Magazine, 22(2006), 12-21.

[7] Muccini, M. "A bright future for organic field-effect transistors". Nat. Mater., 5(2006), 605613.

[8] Capelli, R.; Toffanin, S.; Generali, G.; Usta, H.; Facchetti, A.; Muccini, M. "Organic lightemitting transistors with an efficiency that outperforms the equivalent light-emitting diodes". Nat. Mater., 9(2010), 496-503.

[9] Deng, X.Y. "Light-emitting devices with conjugated polymers". Int. J. Mol. Sci., 12(2011), $1575-1594$. 
[10]M. H. Rezvani, F. Farajollahi, A. Nikfarjam, P. Bakhtiarpour and E. Saydanzad, "Effect of Solvents, Their Mixture and Thermal Annealing on the Performance of Solution Processed Polymer Light-Emitting Diodes", Materials, 6(2013), 1994-2006.

[11]Ahmed Namah Mohamed "Studying the optical properties of thin films prepared from polystyrene doped with DCM dye". 61(2015), 176-181.

[12]M. Maebayashia, T. Matsuoka, S. Koda, R. Hashitani, T. Nishio, S.-ichi. Kimura, "Study on Polystyrene Thin Film on Glass Substrate by Scanning Acoustic Microscope", Elsevier, Polymer", 45(2004), 7563-7569.

[13]O. BaoLi, L. DuXin, "Preparation of Polystyrene/silica Nanocomposites by Radical Copolymerization of Styrene with Silica Macromonomer". Sci. China. Ser. B-Chem., 50(2007), 385-391.

[14] V.M. Zolotarev, B.Z. Volchek and E.N. Vlasova, "Optical constants of industrial polymers in the IR region", Optics and Spectroscopy 101(2006), 716- 723.

[15]G. Streetman Banerjee, "Solid State Electronic Devices" the university of Texas at Austin,(2006)

[16]J. I. Pankove," Optical processes in semiconductors" ,Prentice Hall, New York, (1971).

[17]H. Ulrich, "Introduction to Industrial Polymers" New York, (1982).

[18]M. Balkanski, "Optical Properties of Solids " vol2, Amsterdam, New York. Oxford (1992)

[19]B. O. Seraphin, "Optical Properties of solid New Developments" company, American, Elsevier Publishing-New York, (1976).

[20]Y.T. Ravikiran, M.T. Lagare, M. Sairam, N.N. Mallikajuna, B. Sreebhar, S. Manohar, A.G. MacDiarmid, and T.M. Aminabhavi, "Synthesis, characterization and low frequency AC conductivity of polyaniline/niobium pentoxide composites", Synthetic Metals 156, (2006), 1139-1147.

[21] Sreelalitha Kramadhati, K. Thyagarajan, "Optical Properties of Pure and doped $\left(\mathrm{KnO}_{3} \&\right.$ $\mathrm{MgCl}_{2}$ ) PVA polymer thin films", 6(2013), 15-18.

[22]M. Brodky, "Amorphous Semiconductors" Sepringer- Verlag, Berlin, Heidelberg, (1979).

[23]D. W. Van Krevelen, K. te Nijenhuis, "Properties of Polymers", 3rd edition Elsvier Science B.V. Amsterdam, the Netherland (2009). 